\title{
Characterization of the interactions of $\beta$-amyloid peptides with glycolipid receptors by surface plasmon resonance
}

\author{
Tania Valdes-Gonzalez ${ }^{\mathrm{a}, \mathrm{b}}$, Junichi Inagawa ${ }^{\mathrm{c}}$ and Tatsuo Ido ${ }^{\mathrm{a}, \mathrm{b}, *}$ \\ ${ }^{a}$ Division of Radiopharmaceutical Chemistry, Cyclotron and Radioisotope Center, Tohoku University, \\ Aramaki, Aoba, Sendai 980-8578, Japan \\ ${ }^{\mathrm{b}}$ Graduate School of Pharmaceutical Sciences, Tohoku University, Aramaki, Aoba, Sendai \\ 980-8578, Japan \\ ${ }^{\mathrm{c}}$ Biacore, Tokyo, Japan
}

\begin{abstract}
Interactions between $\beta$-amyloid $(\mathrm{A} \beta$ ) peptides and neuronal membranes play an important role in Alzheimer's disease $(\mathrm{AD})$. Using surface plasmon resonance we assayed a kinetic model to study the interactions of $\mathrm{A} \beta 25-35, \mathrm{~A} \beta 40$ and A $\beta 42$ with surfaces containing single glycolipids (Asialo-GM1, GM1, GD1a or GT1b). The larger peptides interacted with gangliosides stronger than $\mathrm{A} \beta 25-35$, which showed some significant bindings solely at high concentrations under acidic conditions. Only the interactions at low $\mathrm{A} \beta$ concentrations were useful to calculate the kinetic constants. The affinities increased at low $\mathrm{pH}$. The specificity, but not the affinity correlated with the number of sialic acids in the ganglioside sugar moiety. The most important finding in this study, was a special group of sensorgrams with linear association phases that appeared for the interactions of $\mathrm{A} \beta$ with the membranes containing gangliosides, due to the following process: when $\mathrm{A} \beta$ is injected at a critical concentration, the first molecules that interact with the gangliosides remain fixed on the membrane. Next $\mathrm{A} \beta$ molecules bind to these fixed molecules, so that for each $\mathrm{A} \beta$ molecule bound, new binding sites are activated on the surface in a linear ratio, which explains the linear shape of the sensorgrams. This way a laminar-arranged $\mathrm{A} \beta$ accumulate is progressively formed on the membrane surface and fixed there. These linear sensorgrams were not observe with asialo-GM1 or DMPC, which indicates the main role of sialic acid in these interactions. This model for progressive $\mathrm{A} \beta$ deposition could simulate the initial stage of the $\mathrm{A} \beta$ peptide accumulation on cell surfaces.
\end{abstract}

Keywords: $\mathrm{A} \beta$ deposition, gangliosides, surface plasmon resonance

\section{Introduction}

Alzheimer's disease (AD), the major form of progressive senile dementia in the elderly, is pathologically characterized by the deposition of abnormal fibrous protein in senile plaques and in neurofibrillary tangles in the brain. The main component of the senile plaques, $\beta$-Amyloid (A $\beta$ ) protein [1] (a family of $39-43$-residue peptides) is a fragment derived from a much larger amyloid precursor protein (APP) $[2,3]$.

Several studies indicate that $\mathrm{A} \beta$ neurotoxicity may be mediated, in part, by direct interactions between $\mathrm{A} \beta$ and membrane lipids: Arispe et al. [4,5] have showed that $\mathrm{A} \beta 40$ forms cation-selective channels across artificial planar bilayers formed from acidic phospholipids and across excised membrane patches from immortalized hypotalamic GnRH neurons (GT1-7 cells), and they have speculated that the nonregulated $\mathrm{Ca}^{2+}$ influx through these spontaneous channels may provide a mechanism to explain excitoxicity [6]. More recently, they have proved that A $\beta 40$ applied to GT1-7 neurons elevates intracellular

\footnotetext{
*Corresponding author: Tatsuo Ido, Division of Radiopharmaceutical Chemistry, Cyclotron and Radioisotope Center, Tohoku University, Aramaki, Aoba, Sendai 980-8578, Japan. Fax: +81 22217 3485; E-mail: tido@cyric.tohoku.ac.jp.
} 
$\mathrm{Ca}^{2+}$ levels [7]. Terzi et al., using biophysical techniques, have demonstrated that at high concentrations $(200 \mu \mathrm{M}), \mathrm{A} \beta 25-35$ and $\mathrm{A} \beta 40$ form $\beta$-sheet structures upon the addition of phosphatidylcholine (PC)/phosphatidylglycerol (PG) vesicles under neutral conditions $[8,9]$.

In particular, the interaction of $\mathrm{A} \beta$ with the membrane glycolipids has been studied. Using fluorescent dye it was demonstrated that $\mathrm{A} \beta 40$ and $\mathrm{A} \beta 42$ disrupt $\mathrm{PC}$ vesicles only when the liposomes contain gangliosides [10,11], and that these peptides bind selectively to membranes, depending on the type of sugar moiety in the gangliosides. Moreover, the ability of the gangliosides to prevent $\mathrm{A} \beta$ from beta-sheet conformation has been also investigated using circular dichroism. At acidic $\mathrm{pH}$, beta-sheet formation predominates for $\mathrm{A} \beta 40$ and $\mathrm{A} \beta 42$ when they interact with $\mathrm{PC}$ vesicles containing single gangliosides or even mixed gangliosides. At neutral $\mathrm{pH}$, alpha-helix conformation predominates when the peptides interact with PC vesicles containing mixed gangliosides, and beta-sheet formation predominates when they interact with single gangliosides [11,12]. It has been also demonstrated by using Fourier Transform Infrared-Polarized Attenuated Total Reflection (FTIR-PATR) spectroscopy, that A $\beta 40$ forms an antiparallel beta-sheet, the plane of which lies parallel to the membrane surface, inducing dehydration of lipid interfacial groups and perturbation of the acyl chain orientation. This suggests that $\mathrm{A} \beta 40$ imposes negative curvature strain on ganglioside-containing lipid bilayers, thereby disturbing the structure and function of membranes [13].

A kinetic study allows to better characterize the molecular mechanism underlying the interactions of $\mathrm{A} \beta$ with the gangliosides in the cell membrane.

Gangliosides are glycosphingolipids concentrated especially in neuronal membranes [14-16]. Thus, they require cell surface-like presentation to understand their real behavior. We have used in our experiments Surface Plasmon Resonance (SPR) [17] with an HPA sensor chip which allows the presentation of glycolipids in a bilayer microenvironment [18] to study the interaction of $\mathrm{A} \beta 25-35, \mathrm{~A} \beta 40$ and $\mathrm{A} \beta 42$ with liposomes containing asialo-GM1, GM1, GD1a or GT1b at pH 7.4 and 7.0, and under the acidic conditions that characterize $\mathrm{AD}$. Moreover, we have evaluated how the aging of $\mathrm{A} \beta$ peptides affects these interactions.

\section{Methods}

\subsection{Materials}

Peptides $\mathrm{A} \beta 25-35, \mathrm{~A} \beta 40, \mathrm{~A} \beta 42$ and the monosialoganglioside GM1, the disialoganglioside GD1a, the trisialoganglioside GT1b, and the asialo-GM1 were purchased from Sigma, USA. The $n$-Octylglucoside ( $n$-OG) was from Wako, Japan. Dimyristoyl Phosphatidylcholine (DMPC) was purchased from NOF Corp., Japan, and Liposofast apparatus and polycarbonate filters from Avestin, Inc., Canada. Biosensor system BIACORE 2000 and BIAevaluation 3.1 software used for data analysis were from BIACORE, Sweden. All the reagents used in the experiments were of analytical grade.

\subsection{Liposomes containing single gangliosides}

The liposomes were prepared as explains Reference [19]. Briefly, DMPC and pure gangliosides were dissolved in chloroform and mixtures containing DMPC/ganglioside (final ganglioside concentration, $20 \%$ ) were dried in glass vials under vacuum. The mixtures were resuspended by vortexing in HEPES buffer $\mathrm{pH} 7.4$ and placed in a sonic bath for $30 \mathrm{~s}$. Suspensions containing the liposomes were extruded through polycarbonate filters in the Liposofast and injected immediately on the sensor chip flow cells. 


\subsection{HPA chip preparation}

The HPA sensor docked in the BIACORE 2000 biosensor system was washed with $20 \mu 1$ of $20 \mathrm{mM}$ $n$-OG. Then, $30 \mu \mathrm{l}$ of liposome solution were fused at $1 \mu \mathrm{l} / \mathrm{min}$ to the surface of the sensor flow cells to form flat hybrid bilayers and $5 \mu \mathrm{l}$ of $10 \mathrm{mM} \mathrm{NaOH}$ were injected to remove the incompletely fused liposomes. $10 \mathrm{mM}$ HEPES buffered saline, $\mathrm{pH} 7.4$, which contained $150 \mathrm{mM} \mathrm{NaCl}$ was used as a running buffer. All the experiments were performed at $25^{\circ} \mathrm{C}$. The liposomes containing only DMPC or asialo-GM1 were used as controls to determine the non-specific binds and the specificity for sialic acid, respectively.

\subsection{Injection conditions}

In all of the cases the $\mathrm{A} \beta$ peptides were used immediately after being dissolved and for each experiment new peptides from the same lot were used. All the procedures with the peptides were made on ice. The peptides were injected on the HPA flow cells $(15 \mu \mathrm{l}$ at $5 \mu \mathrm{l} / \mathrm{min}$ flow rate) using the multichannel pathway to shorten the experiment, in order to minimize the effects of $\mathrm{A} \beta$ aggregation; thus the sensorgrams were obtained simultaneously for each surface containing glycolipids. Within one set of experiments using the same peptide, the sensor chip surfaces were regenerated with HEPES buffer. After each set of experiments the inlet system was carefully washed with a detergent, $50 \mathrm{mM} \mathrm{NaOH}$ and distilled water and the flow cell surfaces were regenerated as follows: distillated water $-50 \mathrm{mM} \mathrm{NaOH}$ - distilled water.

\section{5. $p H$ effect}

$\mathrm{A} \beta 25-35, \mathrm{~A} \beta 40$ and $\mathrm{A} \beta 42$ were individually dissolved in a $10 \mathrm{mM}$ HEPES buffer, $\mathrm{pH} 7.4,7.0,6.5$ or 6.0 , to obtain concentrations from 400 to $3.65 \mu \mathrm{g} / \mathrm{ml}$, and the same buffers were used as running buffers and buffers for regeneration. The peptides were injected simultaneously on the four flow cells. Specificity and kinetic parameters were determined from the sensorgrams for each peptide concentration as described below.

\subsection{Kinetics of A $\beta$-ganglioside interaction}

Association and dissociation rate constants were calculated by nonlinear fitting of the primary sensorgram data [20] using the BIA evaluation 3.1 software. The dissociation rate constant $\left(k_{\text {off }}\right)$ was derived using the equation

$$
R_{t}=R_{t 0} \mathrm{e}^{-k_{\text {off }}(t-t 0)},
$$

where $R_{t}$ is the response at time $t$ and $R_{t 0}$ is the amplitude of the initial response. The association rate constant $\left(k_{\text {on }}\right)$ can then be derived using the equation

$$
R_{t}=\left[k_{\mathrm{on}} C R_{\max }\left(1-\mathrm{e}^{-\left(k_{\mathrm{on}} C+k_{\mathrm{off}}\right) t}\right)\right] /\left(k_{\mathrm{on}} C+k_{\mathrm{off}}\right),
$$

where $R_{t}$ represents the response at time $t, R_{\max }$ is the maximum response; $C$, the concentration of peptide in solution and $k_{\text {off }}$, the dissociation rate constant. 
Affinities were calculated from rate constants:

$$
K_{\mathrm{D}}=k_{\text {off }} / k_{\text {on }}=1 / K_{\mathrm{A}}
$$

$K_{\mathrm{D}}$ is the dissociation constant and $K_{\mathrm{A}}$, the affinity constant.

\subsection{Seeding effect}

$\mathrm{A} \beta 25-35, \mathrm{~A} \beta 40$ and $\mathrm{A} \beta 42(12.5 \mu \mathrm{M}$ in HEPES, $\mathrm{pH}$ 7.4) were injected on sensor surfaces after individual incubation for $3 \mathrm{~h}$ at $37^{\circ} \mathrm{C}$ in a block incubator.

\section{Results}

\subsection{HPA chip preparation}

The liposomes were prepared from DMPC and single glycolipids and then injected onto the flow cells to form bilayer membranes on the surfaces of the HPA sensor chips. The HPA sensor chip was selected because in experiments with liposomes it has shown about a ten times higher capacity for molecular binding as liposomal surface, than the commonly used CM5 sensor chip [21]. Monolayer surfaces containing the glycolipids which were obtained injecting $\mathrm{NaOH}$ on the bilayer surfaces, typically showed RU values around 2000 for DMPC, GM1 20\% and asialo-GM1 20\% and about 1000 for polysialogangliosides (GD1a and GT1b, 20\% and 15\%, respectively). Liposomes containing GT1b 15\% were selected for experiments because their monolayer yields with respect to the bilayer were higher than for GT1b $20 \%$ due to the fact that the higher hydrophobicity/hydrophilicity ratio facilitates a better liposomes packing. All the prepared surfaces provided a stable baseline for the determination of $\mathrm{A} \beta$ binding specificity and kinetics.

\subsection{A $\beta$-ganglioside binding kinetics}

SPR was used to evaluate the interaction of $\mathrm{A} \beta$ peptides with the surfaces containing gangliosides. The profiles of $\mathrm{A} \beta 40, \mathrm{~A} \beta 42$ and $\mathrm{A} \beta 25-35$ binding the surfaces at $\mathrm{pH} 7.4$ are shown in Figs 1, 2 and 3, respectively.

For $\mathrm{A} \beta 40$ (Fig. 1) the interactions depended on the number of molecules of sialic acid in the ganglioside sugar moiety because the kinetics of the $\mathrm{A} \beta 40$ binding to surfaces containing monosialo gangliosides and polysialo gangliosides were different. For surfaces containing GD1a or GT1b, the sensorgrams showed normal shapes at low $\mathrm{A} \beta 40$ concentrations, but at $5.8 \mu \mathrm{M}$, the association phase of the sensorgrams became linear and the dissociation was slow. At $11.5 \mu \mathrm{M}$ the sensorgrams recovered the normal shape and RU values dramatically increased with a rapid association rate, but the dissociation was still slow. From this concentration on, the $R_{\max }$ decreased with the increasing $\mathrm{A} \beta 40$ concentration and the dissociation phases became faster, which indicates that at higher concentrations the interactions peptidepeptide in solution predominate. The RU values for the interactions of $\mathrm{A} \beta 40$ at $5.8 \mu \mathrm{M}$ with GT1b were higher than those with GD1a. In the sensorgrams describing the interaction of $\mathrm{A} \beta 40$ with surfaces containing GM1 (Fig. 1A), the linear shape did not appear, but from $23.1 \mu \mathrm{M}$ on, the $R_{\max }$ decreased due to the effect of peptide-peptide interactions in $\mathrm{A} \beta 40$ solution. 
A

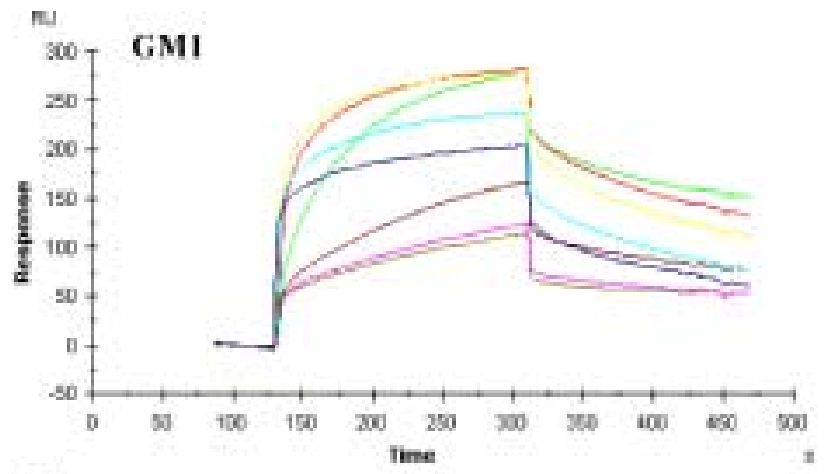

B

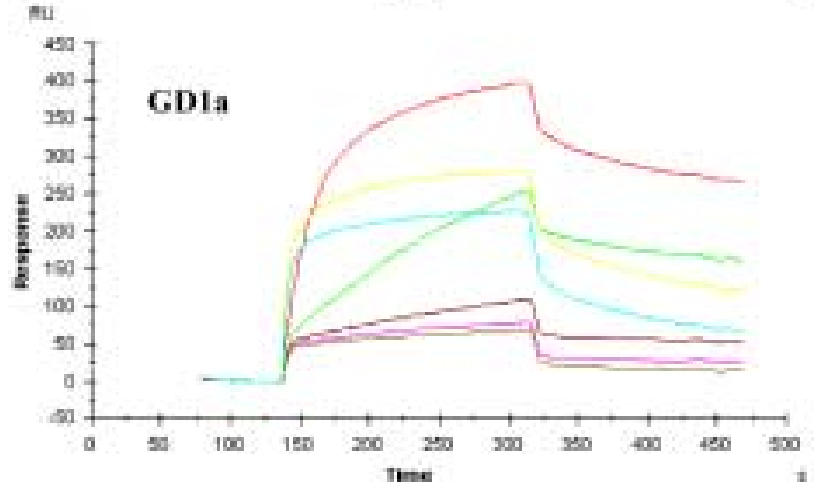

C

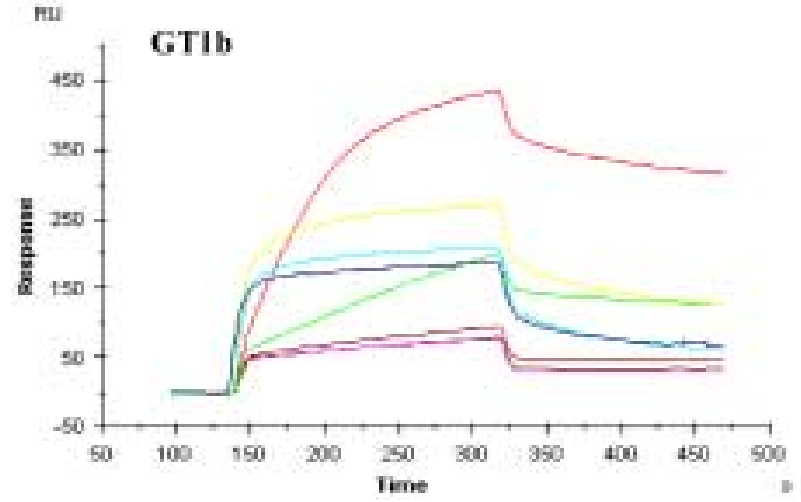

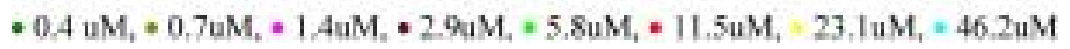

Fig. 1. Overlays plots of $\mathrm{A} \beta 40$ at different concentrations at $\mathrm{pH} 7.4$ binding to surfaces containing (A) GM1, (B) GD1a or (C) GT1b fused to HPA sensor chip.

For $\mathrm{A} \beta 42$ (Fig. 2), at $5.5 \mu \mathrm{M}$ the association phase of the sensorgrams became linear in the interactions with all the surfaces containing gangliosides, with the highest $R_{\max }$ values for GM1- and the lowest for GD1a-containing surfaces. Similarly to A $\beta 40$, at higher A $\beta 42$ concentrations the specificity decreased with the increasing concentration.

The RU values and affinity for the A $\beta$ interactions with DMPC or asialo-GM1 surfaces were low. Only the interactions with at higher $\mathrm{A} \beta$ concentrations gave slightly higher RU, due to the interactions 

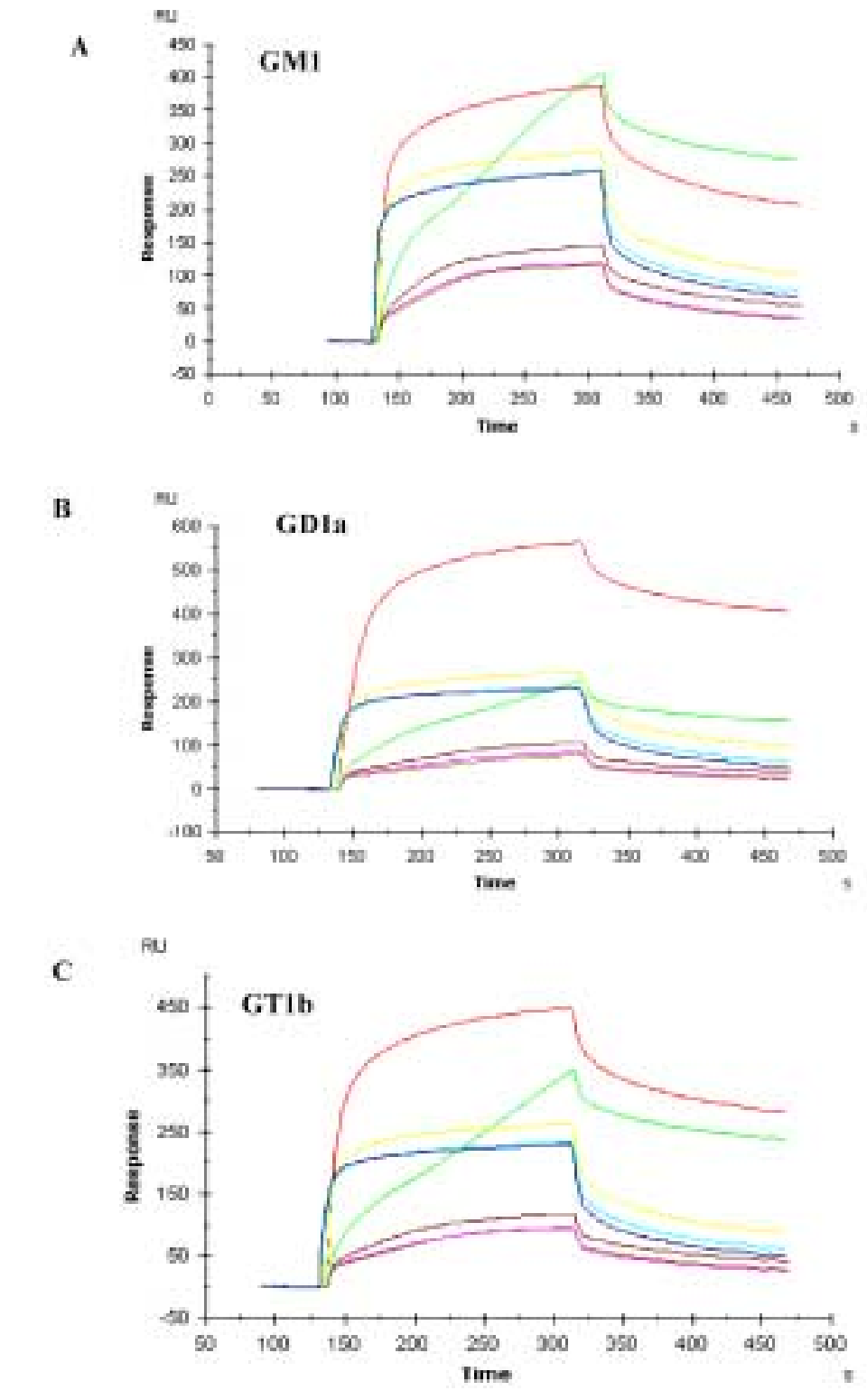

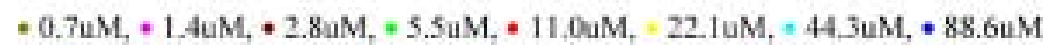

Fig. 2. Overlays plots of $\mathrm{A} \beta 42$ at different concentrations at $\mathrm{pH} 7.4$ binding to surfaces containing (A) GM1, (B) GD1a or (C) GT1b fused to HPA sensor chip.

peptide-peptide in solution, but in no cases was the linear shape observed for the interactions of $\mathrm{A} \beta$ with these glycolipids which do not contain sialic acid (Fig. 4).

Under acidic conditions, all the experiments gave lower RU than those at neutral $\mathrm{pH}$. Besides, the sensorgrams became linear at lower $\mathrm{A} \beta$ concentrations, even for the interaction of $\mathrm{A} \beta 40$ with surfaces containing GM1, where the linear shape was not observed at all at the neutral pH nor pH 7.4 (Fig. 5). 

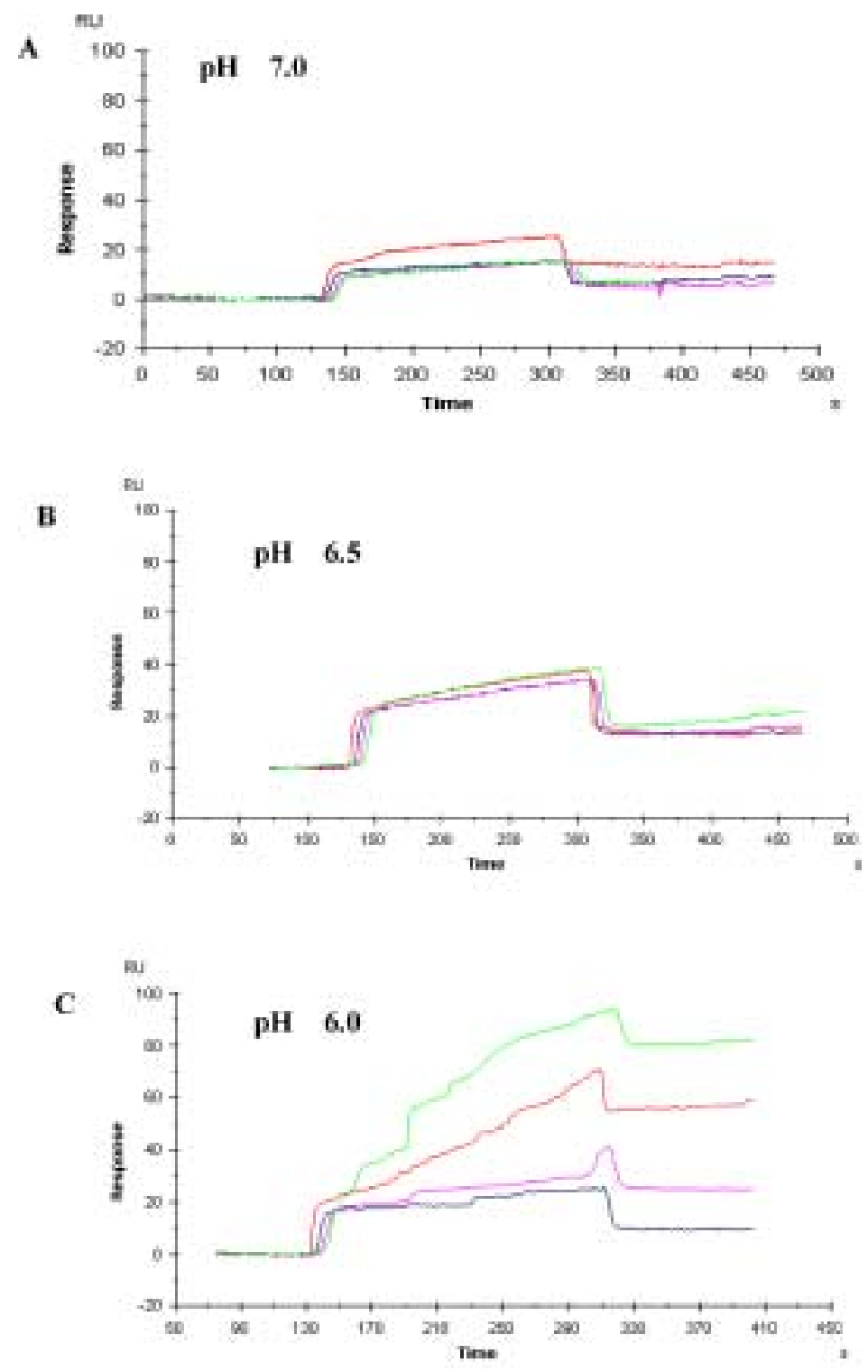

- asialo-GMI, * GMI, * GDla, * GT1b

Fig. 3. Sensorgrams of $\mathrm{A} \beta 25-35(12.5 \mu \mathrm{M})$ binding to surfaces containing GM1, GD1a, GT1b or DMPC alone at pH (A) 7.0, (B) 6.5 and (C) 6.0 .

The interactions of $\mathrm{A} \beta 25-35$ with the ganglioside-containing surfaces under neutral conditions (Fig. 3A) were characterized by low specificity at any concentration. Nevertheless, with the decreasing $\mathrm{pH}$, the $\mathrm{RU}$ values increased, the association phases of the sensorgrams became linear, and the dissociation phases, slower (Fig. 3B,C). At pH 6.0 the linear shape dramatically increased for the interactions with surfaces containing GD1a and GT1b. 


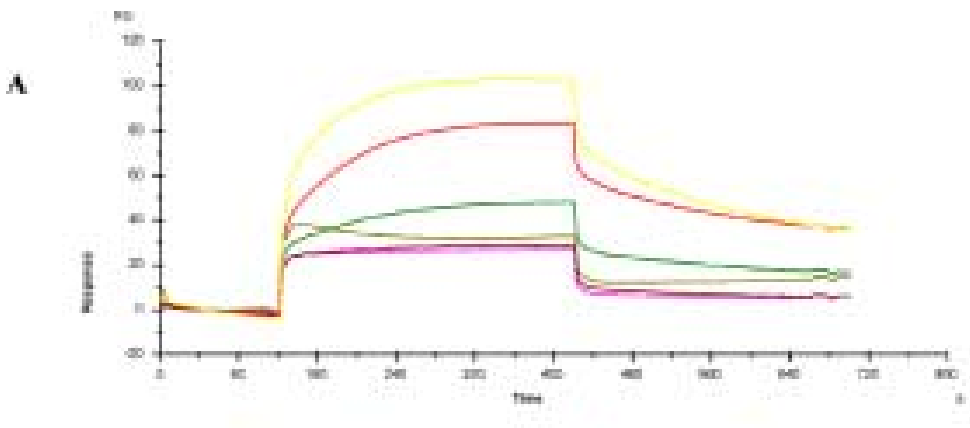

$\cdot 0.7 \mathrm{uM}, \cdot 1.4 \mathrm{uM}, \cdot 2.9 \mathrm{uM}, \cdot 5.8 \mathrm{uM}, \cdot 11.5 \mathrm{uM},-23.1 \mathrm{uM}$

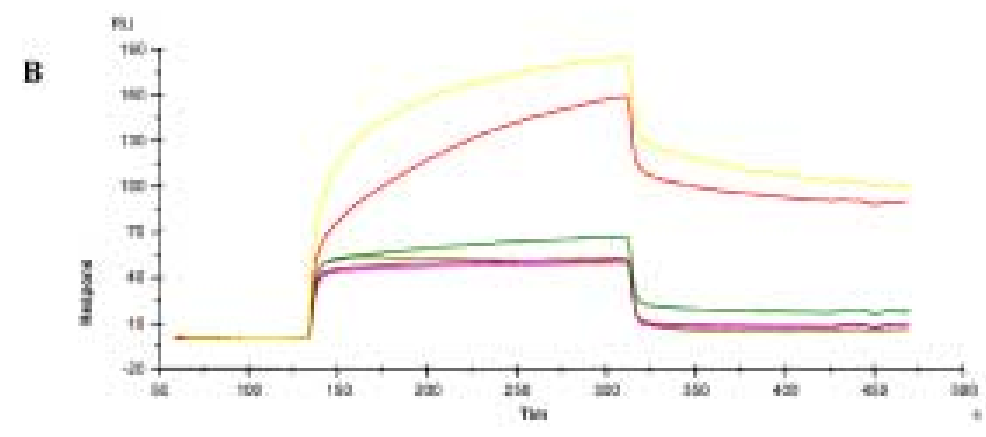

- 0.7uM, + 1.4uM, * 2.8uM, - 5.5uM, + 11.0uM, *22.1uM

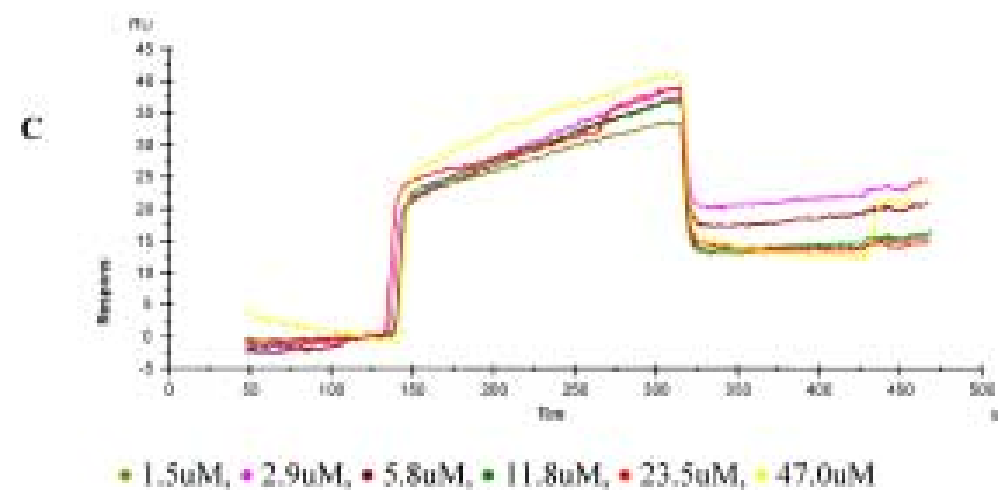

Fig. 4. Sensorgrams for interactions of (A) A $\beta 40$ with asialo-GM1-containing surfaces and (B) A $\beta 42$ and (C) A $\beta 25-35$ with DMPC surfaces at $\mathrm{pH}$ 7.4.

\subsection{A -ganglioside affinity}

With this experimental model we tried to simulate the interactions of $\mathrm{A} \beta$ with glycolipids in vivo, minimizing the damage of the surfaces. Thus, we used drastic surface regeneration only after each set of experiments had finished, which imply that within one set of experiments with the same peptide at the same $\mathrm{pH}$, the surfaces containing gangliosides were not regenerated completely. It means that, 

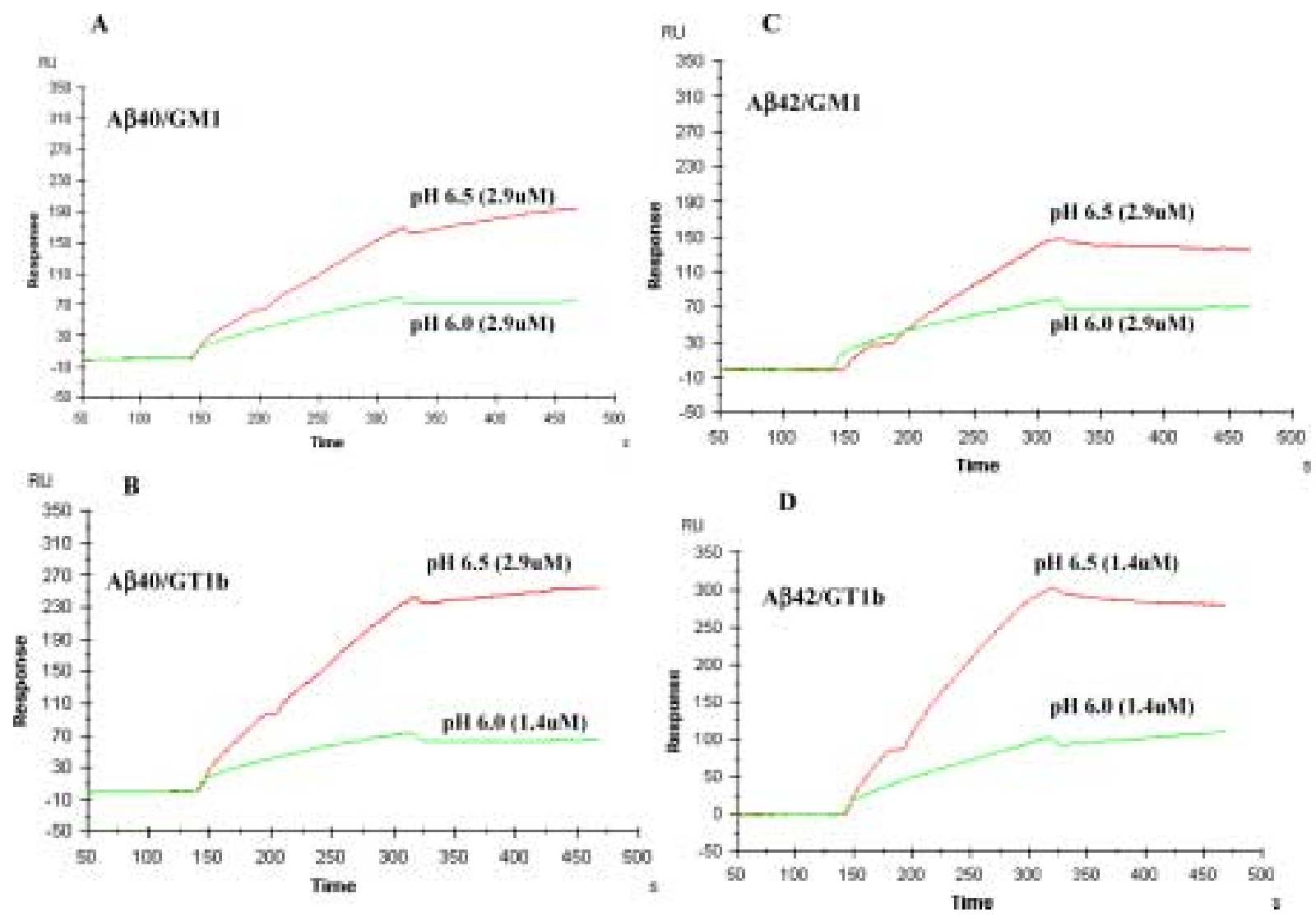

Fig. 5. Overlays plots representing the critical concentrations at which the linear shape appears at $\mathrm{pH} 6.5$ and 6.0 for the interaction of (A) A $\beta 40 / G M 1$, (B) A $\beta 40 / G T 1 b$, (C) A $\beta 42 / G M 1$ and (D) A $\beta 40 / G T 1 b$.

especially in the case of injections at higher $\mathrm{A} \beta$ concentrations, peptides were not completely removed from the surfaces. This fact brings the inconvenience of heterogeneous interactions, because $\mathrm{A} \beta$ binds not only to gangliosides, but also bind to each other on the surfaces, which made difficult to obtain useful quantitative data. Because of that, in this study to calculate the affinities $\left(1 / K_{\mathrm{D}}\right)$ we used only the kinetic constants for the interactions of $\mathrm{A} \beta$ at low concentrations, where the effect peptide-peptide is no significant and in no case the kinetic constants corresponding to the linear sensorgrams were used in the calculations (Table 1). Although these affinity values are useful parameters to compare the interactions of the different $\mathrm{A} \beta$ peptides with surfaces containing gangliosides in our experiments, due to the complexity of the interactions should not be taken as absolute data.

As Table 1 shows, in most of the cases, the affinity values were high, especially at low $\mathrm{pH}$ and in general were stronger for $\mathrm{A} \beta 40$ than for $\mathrm{A} \beta 42$. At $\mathrm{pH} 7.4$ and 7.0 the $1 / K_{\mathrm{D}}$ were higher for the interactions with polysialo than with the monosialo-ganglioside. At pH 6.5 the affinity constants were similar for GM1 and GT1b and at $\mathrm{pH} 6.0, \mathrm{~A} \beta$ peptides showed the lowest affinity with GT1b. The $1 / K_{\mathrm{D}}$ values for surfaces containing GD1a, in general, remained unchanged. The low $\mathrm{pH}$ promoted an increase in the affinity of the interactions with gangliosides, especially for $\mathrm{A} \beta 42$. 
Table 1

Affinity constants for the interactions of $\mathrm{A} \beta 40$ and $\mathrm{A} \beta 42$ with ganglioside-containing surfaces at different $\mathrm{pH}$

\begin{tabular}{|c|c|c|c|}
\hline \multirow[t]{2}{*}{$\overline{\mathrm{pH}}$} & \multirow[t]{2}{*}{ Ganglioside } & \multicolumn{2}{|c|}{$K_{\mathrm{D}}(\mathrm{M})$} \\
\hline & & $\mathrm{A} \beta 40$ & $\mathrm{~A} \beta 42$ \\
\hline \multirow[t]{6}{*}{$\overline{7.4}$} & GM1 & $1.32 \times 10^{-6}$ & $1.4 \times 10^{-6}$ \\
\hline & & $1.4^{* *}$ & 2.2 \\
\hline & GD1a & $1.65 \times 10^{-7}$ & $1.1 \times 10^{-7}$ \\
\hline & & 1.1 & 0.01 \\
\hline & GT1b & $2.89 \times 10^{-7}$ & $4.2 \times 10^{-7}$ \\
\hline & & 3.0 & 1.5 \\
\hline \multirow[t]{6}{*}{7.0} & GM1 & $1.29 \times 10^{-7}$ & $1.9 \times 10^{-6}$ \\
\hline & & 0.5 & 0.9 \\
\hline & GD1a & $2.69 \times 10^{-7}$ & $3.3 \times 10^{-7}$ \\
\hline & & 2.5 & 1.6 \\
\hline & GT1b & $1.63 \times 10^{-7}$ & $8.5 \times 10^{-7}$ \\
\hline & & 0.9 & 5.3 \\
\hline \multirow[t]{6}{*}{6.5} & GM1 & $5.72 \times 10^{-9}$ & $4.3 \times 10^{-9}$ \\
\hline & & 1.4 & \\
\hline & GD1a & $1.38 \times 10^{-7}$ & $4.3 \times 10^{-7}$ \\
\hline & & 0.9 & 0.9 \\
\hline & GT1b & $6.20 \times 10^{-9}$ & $4.8 \times 10^{-9}$ \\
\hline & & 0.3 & 1.4 \\
\hline \multirow[t]{6}{*}{6.0} & GM1 & $4.69 \times 10^{-9}$ & $1.5 \times 10^{-10}$ \\
\hline & & 1.2 & 2.1 \\
\hline & GD1a & $4.57 \times 10^{-8}$ & $1.7 \times 10^{-8}$ \\
\hline & & 3.5 & 1.5 \\
\hline & GT1b & $8.62 \times 10^{-13}$ & $2.9 \times 10^{-10}$ \\
\hline & & 0.9 & 3.1 \\
\hline \multicolumn{4}{|c|}{$\begin{array}{l}\text { The association rate }\left(k_{\mathrm{on}}\right) \text {, the dissociation rate }\left(k_{\mathrm{off}}\right) \text { and } \\
\text { the real dissociation constant }\left(K_{\mathrm{DR}}\right) \text { are the mean values for } \\
\text { the interactions of } \mathrm{A} \beta 40 \text { at low concentrations (lower than } \\
5.8 \mu \mathrm{M}) \text {. }\end{array}$} \\
\hline
\end{tabular}

\subsection{Effect of seeding on $A \beta$ binding to liposomes}

It has been demonstrated that during the aging process, $\mathrm{A} \beta$ assembles into fibrils [22]. Under our experimental conditions the formation of $\mathrm{A} \beta$ aggregates was accelerated by incubation at $37^{\circ} \mathrm{C}$ of freshly dissolved $\mathrm{A} \beta$ at very low concentrations. A short time after incubation the interactions of $\mathrm{A} \beta$ with surfaces were measured, and it was found that the interactions of $\mathrm{A} \beta 40$ and $\mathrm{A} \beta 42$ with all the surfaces (Fig. 6) increased. Even the $R_{\max }$ for the interactions with surfaces without gangliosides became very high (about 10 times higher than for the interaction of peptides without incubation). For A $\beta 25-35$, the RU values increased, but less than in the cases of $\mathrm{A} \beta 40$ and $\mathrm{A} \beta 42$, suggesting that aggregate formation due to incubation had a higher effect on the larger peptides than on $\mathrm{A} \beta 25-35$. All the interactions showed fast association rates, but the dissociation rates were similarly rapid and the affinities very low, suggesting that the formed aggregates only adsorb onto the liposome surfaces, being rapidly washed out after the injections finished. 
A

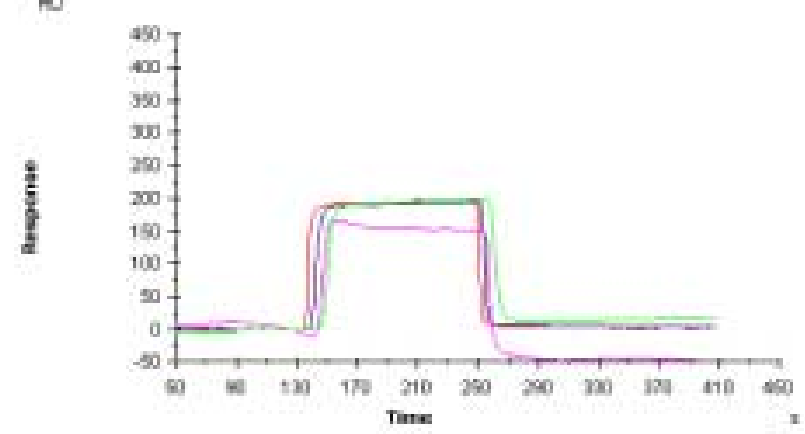

$\mathbf{B}$

C
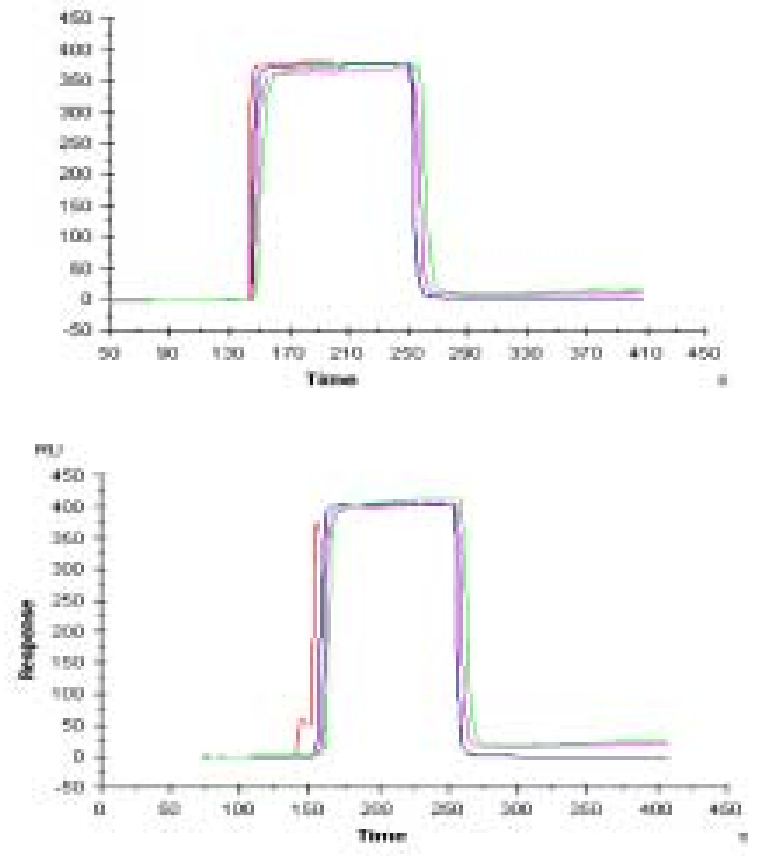

- asialo-GMI, - GMI, - GDIa, - GTIb

Fig. 6. Effect of incubation on the $\mathrm{A} \beta$-ganglioside interactions. (A) $\mathrm{A} \beta 25-35$, (B) $\mathrm{A} \beta 40$ and (C) $\mathrm{A} \beta 42$.

\section{Discussion}

Previous investigations have demonstrated that the gangliosides play a role in the interactions of $\mathrm{A} \beta$ peptides with the cell membrane. In this study, using SPR, we simulated the interaction of $\mathrm{A} \beta$ with cell membrane by consecutive injections of $\mathrm{A} \beta$ under different conditions, on ganglioside-containing surfaces fused onto an HPA sensor chip.

As we detailed in the Results, the interactions of $\mathrm{A} \beta$ peptides with surfaces containing single gangliosides depended on the $\mathrm{A} \beta$ concentration, the ganglioside sugar moiety, and the $\mathrm{pH}$. Actually, only the affinity constants calculated at low $\mathrm{A} \beta$ concentrations gave useful information about the interactions with glycolipids, because at higher $\mathrm{A} \beta$ concentrations the $\mathrm{A} \beta-\mathrm{A} \beta$ interactions "masked" the real values. 
The larger peptides, $\mathrm{A} \beta 40$ and $\mathrm{A} \beta 42$, interacted more with gangliosides than $\mathrm{A} \beta 25$, which showed some significant interactions only at high concentrations and under acidic conditions. The ability of gangliosides to interact with $\mathrm{A} \beta 40$ and $\mathrm{A} \beta 42$ is proportional to the negative charges in the membrane [11]. This fact explains the different specificities observed in the interaction of $\mathrm{A} \beta$ with surfaces containing single mono-, di-, or tri-sialogangliosides although these differences were not always observed for the affinity constants. The acidic conditions promoted the increase of the affinities in general, and due to the fact that for di- and tri-sialogangliosides more negative charged groups activate at low $\mathrm{pH}$ [23], the affinities of $\mathrm{A} \beta$ for polysialo were more affected than those for the mono-sialo gangliosides.

Nevertheless, the most significant finding in our experiments are the two different groups of $\mathrm{A} \beta$-ganglioside interactions: those that promoted a linear shape of the sensorgrams and those that do not. Our results suggest that the linear shape is related with the accumulation of $\mathrm{A} \beta$ on the membranes according to the following kinetic process: at low concentrations $\mathrm{A} \beta$ interacts directly with the gangliosides (the sensorgrams have normal curves at low concentrations with high affinity). With the increasing $\mathrm{A} \beta$ concentration, some molecules remain bound to gangliosides even during the dissociation phase after finishing the injection. The number of these $\mathrm{A} \beta$ molecules fixed to the gangliosides increases proportionally with the concentration, to form an $\mathrm{A} \beta$ layer fixed on the surface containing gangliosides. Consequently, from a determined concentration the newly injected $\mathrm{A} \beta$ does not bind only to the gangliosides, but to the $\mathrm{A} \beta$ fixed on the surface. This way a laminar-arranged $\mathrm{A} \beta$ accumulate is progressively formed on the membrane surface and fixed there. The affinity for these accumulate formations is defined by the binding of $\mathrm{A} \beta$ in solution to $\mathrm{A} \beta$ fixed in the surface, where for each $\mathrm{A} \beta$ molecule bound, new binding sites are activated on the surface in a linear ratio, which explains the linear shape of the sensorgrams.

The dramatic increase of RU with the injection next to the critical concentrations is due to the fact that at higher $\mathrm{A} \beta$ concentrations, the peptide-peptide aggregation in solutions increases and when $\mathrm{A} \beta$ is injected, interacts with the $\mathrm{A} \beta$ molecules fixed on the liposome surfaces as aggregates. At much higher concentrations, the effect of peptide-peptide aggregations in solution increases, producing larger $\mathrm{A} \beta-\mathrm{A} \beta$ aggregates with less interaction sites available due to steric effects. This explains the lower interaction of $\mathrm{A} \beta$ with the liposome surfaces observed at those concentrations.

The fact that in general, GM1 presents more similarities with GT1b than with GD1a indicates that not only the number of sialic acid in the sugar moiety is important, also their availability in the membrane affects the interactions with $\mathrm{A} \beta$. At $\mathrm{pH} 7.4$ we did not observe the linear shape for $\mathrm{A} \beta 40$ with GM1 under our conditions (GM1 liposome 20\%), which indicates the lower ability of A $\beta 40$ for accumulation on the membranes. Maybe higher concentration of GM1 in the surfaces is necessary to observe the linear shape, similar to the experiments on conformational changes where high percentage of GM1 in the liposomes was required to make the changes observable [13].

The interactions with DMPC and asialo-GM1, showed faster dissociation rates, which indicates that the peptides were completely removed from the surfaces after the injection have finished.

Experiments on $\mathrm{A} \beta$ aging indicated that very large aggregates formed due to incubation do not bind to gangliosides, it means that $\mathrm{A} \beta$ forms the laminar-arranged deposition on the membranes containing gangliosides only when $\mathrm{A} \beta$ interacts as $\mathrm{A} \beta$ molecules or as very small $\mathrm{A} \beta$ oligomers; larger aggregates do not accumulate on the surfaces.

All these results taken together indicate that the interaction of $\mathrm{A} \beta$ with the uniform gangliosidecontaining surfaces, it means surfaces containing clusters of same kind of gangliosides, may promote $\mathrm{A} \beta$ deposition. Actually, in the normal brain the gangliosides are presented in the membrane as a mixture of different gangliosides, thus the probability of $\mathrm{A} \beta$ deposition under normal conditions could be 
low, according previous investigations [11]. Nevertheless, some neurological disorders that promote dramatic changes in the membrane ganglioside composition [24-28], may propitiate modifications in the $\mathrm{A} \beta$ interaction with the cell surfaces and this way, $\mathrm{A} \beta$ deposition. It could be interesting to investigate how $\mathrm{A} \beta$ interacts with surfaces containing the composition of membrane ganglioside in the normal brain, as well as whether or not the imbalance in this normal composition is involved in the $\mathrm{A} \beta$ accumulation on the cell membrane.

In summary, using SPR we have shown here that $\mathrm{A} \beta$ peptides interact with surfaces containing gangliosides depending on $\mathrm{A} \beta$ concentration, ganglioside sugar moiety and $\mathrm{pH}$. Two different kinds of interactions are distinguished: the normal interactions and the interactions where the association phase of the sensorgram become linear, which we associate with the accumulation of $\mathrm{A} \beta$ on the membranes. This process is not unique for $\mathrm{A} \beta$; in previous investigations concerning the interaction of several neuropeptides with gangliosides [19], we found that Substance P also gave lineal sensorgrams, when interacted with uniform surfaces containing gangliosides.

The difference between the specificities and the affinities of the bindings indicates that not only the number of sialic acid in the sugar moiety defines these interactions, but also their steric availability in the membrane is important. We propose a mechanism to explain the formation of the $\mathrm{A} \beta$ laminar accumulation on uniform ganglioside-containing surfaces, which simulate the initial stage of the $\mathrm{A} \beta$ peptide accumulation on cell membrane.

\section{References}

[1] G.C. Glenner and C.W. Wong, Alzheimer's disease: initial report of the purification and characterization of a novel cerebrovascular amyloid protein, Biochem. Biophys. Res. Comm. 120 (1984), 885-890.

[2] J. Kang, H.-G. Lemaire, A. Unterbeck, J.M. Salbaum, C.L. Masters, K.H. Grezeschik, G. Multhaup, K. Beyreuther and B. Muller-Hill, The precursor of Alzheimer's disease amyloid A4 protein resembles a cell-surface receptor, Nature 325 (1987), 733-736.

[3] D. Goldgaber, M.I. Lerman, O.W. McBride, U. Saffiotti and D.C. Gajdusek, Characterization and chromosomal localization of a cDNA encoding brain amyloid of Alzheimer's disease, Science 235 (1987), 877-880.

[4] E. Terzi, G. Holzemann and J. Seeling, Alzheimer beta-amyloid peptide 25-35: electrostatic interactions with phospholipid membranes, Biochem. 33 (1994), 7434-7441.

[5] E. Terzi, G. Holzemann and J. Seeling, Self-association of beta-amyloid peptide (1-40) in solution and binding to lipid membranes, J. Mol. Biol. 252 (1995), 633-642.

[6] N. Arispe, H.B. Pollard and E. Rojas, Giant multilevel cation channels formed by Alzheimer disease amyloid $\beta$-protein [A BP-(1-40)] in bilayer membranes, Proc. Natl. Acad. Sci. USA 90 (1993), 10 573-10 577.

[7] N. Arispe, H.B. Pollard and E. Rojas, $\mathrm{Zn}^{2+}$ interaction with Alzheimer amyloid protein calcium channels, Proc. Natl. Acad. Sci. USA 93 (1996), 1710-1715.

[8] M. Kawara, N. Arispe, Y. Kuroda and E. Rojas, Alzheimer's - amyloid, human islet amylin, and prion protein fragment evoke intracellular free calcium elevations by a common mechanism in a hypothalamic gnrh neuronal cell line, J. Biol. Chem. 275 (2000), 14077-14 083.

[9] M. Kawara, N. Arispe, Y. Kuroda and E. Rojas, Alzheimer's disease amyloid beta-protein forms $\mathrm{Zn}^{2+}$-sensitive, selective cation channels across excised membrane patches from hypothalamic neurons, J. Biophys. 73 (1997), 67-75.

[10] J. MacLaurin and A.J. Chakrabatty, Membrane disruption by Alzheimer - amyloid peptides mediated through specific binding to either phospholipids or gangliosides. Implications for neurotoxicity, J. Biol. Chem. 271 (1996), 26 482-26 489.

[11] J. MacLaurin, T. Franklin, P. Fraser and A. Chakrabatty, Structural transitions associated with the interaction of Alzheimer - amyloid peptides with gangliosides, J. Biol. Chem. 273 (1998), 4506-4515.

[12] L. Choo-Smith, W. Garzon-Rodriguez, C. Glabe and W.K. Surewicz, Acceleration of amyloid fibril formation by specific binding of A(1-40) peptide to ganglioside-containing membrane vesicles, J. Biol. Chem. 272 (1997), 22 987-22 990.

[13] K. Matsuzaki and C. Horikiri, Interactions of amyloid beta-peptide (1-40) with ganglioside-containing membranes, Biochem. 38 (1999), 4137-4142.

[14] Y. Nagai, Functional roles of gangliosides in bio-signaling, Behav. Brain Res. 66 (1995), 99-104.

[15] P.D. Thomas and G.J. Brewer, Gangliosides and synaptic transmission, Biochim. Biophys. Acta 1031 (1990), $277-289$. 
[16] H. Wiegandt, The chemical constitution of gangliosides of the vertebrate nervous system, Behav. Brain Res. 66 (1995), 85-97.

[17] G.M. Kuziemko, M. Stroh and R.C. Stevens, Cholera toxin binding affinity and specificity for gangliosides determined by surface plasmon resonance, Biochem. 35 (1996), 6375-6384.

[18] B. Harrinson, R. MacKenzie, T. Hirama, K.K. Lee and E. Altman, A kinetic approach to the characterization of an IgM specific for the glycolipid asialo-GM1, J. Immunol. Meth. 212 (1998), 29-30.

[19] T. Valdes-Gonzalez, J. Inagawa and T. Ido, Neuropeptides interact with glycolipid receptors a surface plasmon resonance study, Peptides 22 (2001), 1099-1105.

[20] L.K. Simmons, P.C. May, K.J. Tomaselli, R.E. Rydel, K.S. Fuson, E.F. Brigham, S. Wright, I. Lieberburg, G.W. Becker, D.N. Brems and W.Y. Li, Secondary structure of amyloid beta peptide correlates with neurotoxic activity in vitro, Mol. Pharmacol. 45 (1994), 373-379.

[21] R. MacKenzie, T. Hirama, K. Lee, E. Altman and N.M. Young, Quantitative analysis of bacterial toxin affinity and specificity for glycolipid receptors by surface plasmon resonance, J. Biol. Chem. 272 (1997), 5533-5538.

[22] L.K. Simmons, P.C. May, K.J. Tomaselli, R.E. Rydel, K.S. Fuson, E.F. Brigham, S. Wright, I. Lieberburg, G.W. Becker, D.N. Brems and W.Y. Li, Mol. Pharmcol. 45 (1993), 373-379.

[23] M. Gonzalez, N. Lezcano, M. Celis and D. Fidelio, Interactions of alpha-MHS and substance P with interfaces containing gangliosides, Peptides 17 (1996), 269-274.

[24] P.B. Crino, M.D. Ullman, B.A. Vogt, E.D. Bird and L. Volicer, Brain gangliosides in dementia of the Alzheimer type, Arch. Neurol. 46 (1989), 398-401.

[25] I. Kracun, S. Kalanj, J. Talan-Hranilovic and Cosovic, Cortical distribution of gangliosides in Alzheimer's disease, Neurochem. Int. 20 (1992), 433-438.

[26] L. Svennerholm and C. Gottfries, Membrane lipids, selectively diminished in Alzheimer brains, suggest synapse loss as a primary event in early-onset form (type I) and demyelination in late-onset form (type II), J. Neurochem. 62 (1994), $1039-1047$.

[27] T. Valdes-Gonzalez, Y. Morita, K. Suzuki and T. Ido, Excitotoxicity induces changes in rat brain gangliosides, Neuroscience Res. 39 (2001), 197-203.

[28] H. Rahamann, Brain gangliosides and memory formation, Brain Res. 66 (1995), 105-116. 


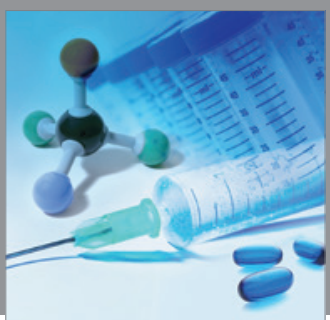

International Journal of

Medicinal Chemistry

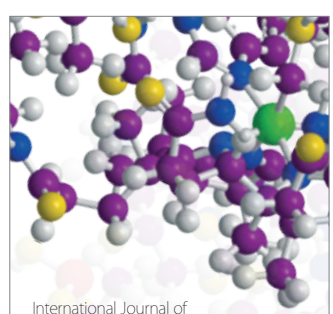

Carbohydrate Chemistry

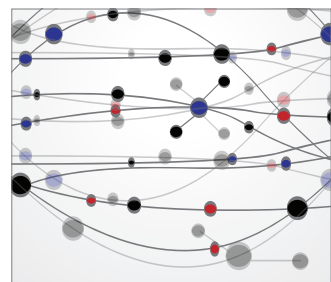

The Scientific World Journal
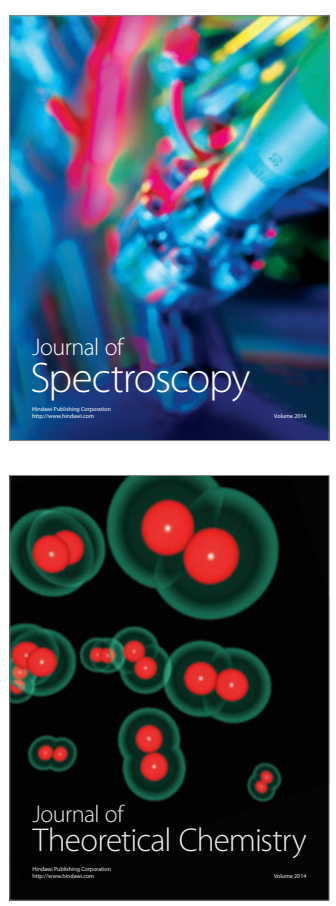
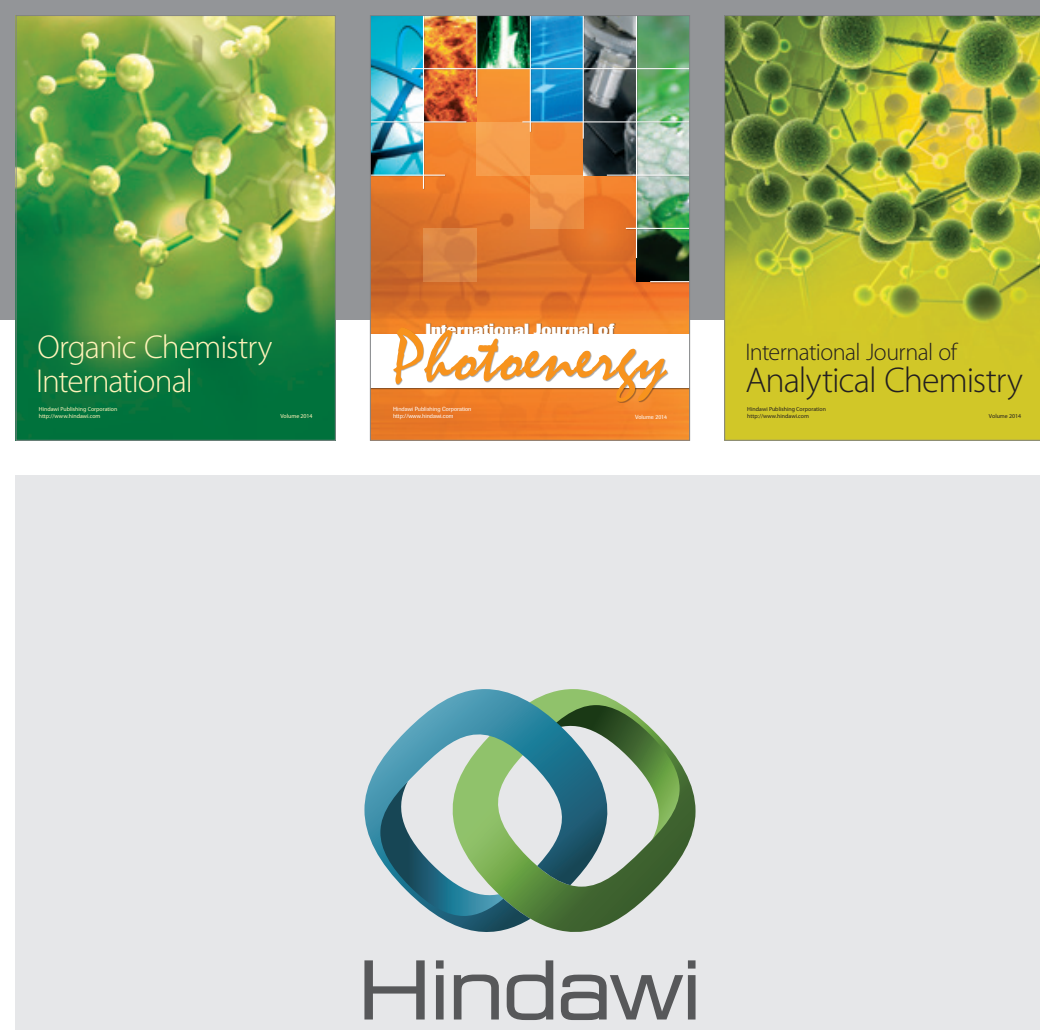

Submit your manuscripts at

http://www.hindawi.com
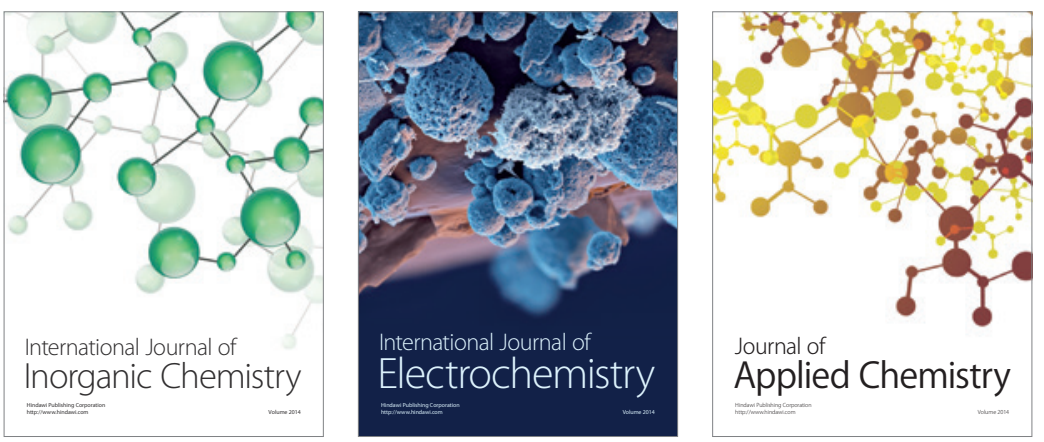

Journal of

Applied Chemistry
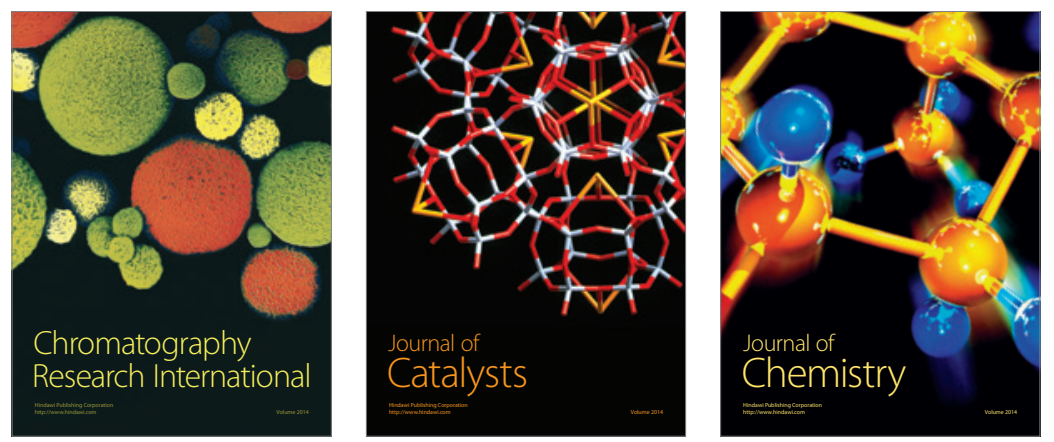
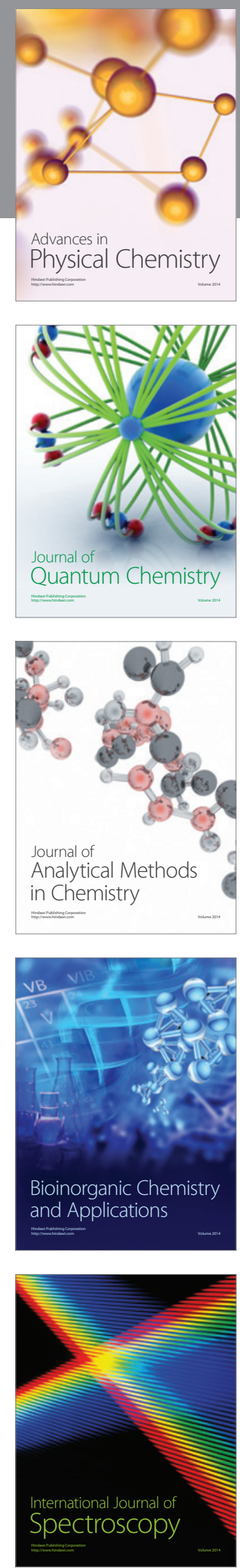